\title{
InGaN/Si Double-Junction Photocathode for Unassisted Solar
}

\section{Water Splitting}

Srinivas Vanka ${ }^{1}$, Baowen Zhou ${ }^{1}$, Rasha A. Awni' ${ }^{2}$, Zhaoning Song ${ }^{2}$, Faqrul A. Chowdhury ${ }^{3,4}$, Xuedong Liu ${ }^{5}$, Hamed Hajibabaei ${ }^{6}$, Wen $\mathrm{Shi}^{7}$, Yixin Xiao ${ }^{1}$, Ishtiaque A. Navid ${ }^{1}$, Ayush Pandey ${ }^{1}$, Rong Chen ${ }^{8}$, Gianluigi A. Botton ${ }^{7}$, Thomas W. Hamann ${ }^{6}$, Dunwei Wang ${ }^{8}$, Yanfa Yan ${ }^{2}$, and

$$
\text { Zetian } \mathrm{Mi}^{1 *}
$$

${ }^{I}$ Department of Electrical Engineering and Computer Science, University of Michigan, Ann Arbor, 1301 Beal Avenue, Ann Arbor, MI 48109, USA

${ }^{2}$ Department of Physics and Astronomy, and Wright Center for Photovoltaics Innovation and Commercialization (PVIC), University of Toledo, Toledo OH 43606, USA

${ }^{3}$ Department of Physics, McGill University, 3600 University Street, Montreal, Québec H3A 2T8,

Canada

${ }^{4}$ Department of Engineering Physics, Polytechnique Montreal, 2500 Chemin de Polytechnique Montreal, Quebec, H3T 1J4, Canada

${ }^{5}$ Facility for Electron Microscopy Research, McGill University, 3640 University Street, Montreal, Quebec H3A 0C7, Canada

${ }^{6}$ Department of Chemistry, Michigan State University, 578 S Shaw Lane, RM 310 East Lansing, MI 48824-1322, USA

${ }^{7}$ Department of Materials Science and Engineering, McMaster University, 1280 Main Street West, Hamilton, Ontario, L8S 4M1, Canada

${ }^{8}$ Department of Chemistry, Boston College, 2609 Beacon St., Chestnut Hill, MA 02467, USA 


\section{Section S1. Methods Section}

Growth of $\boldsymbol{p}^{+}$-InGaN/tunnel junction nanowires on $\boldsymbol{n}^{+}-\boldsymbol{p}$ Si. In this study, InGaN nanowire arrays were grown (see Figure 1(b)) on $n^{+}-p$ Si substrates ${ }^{1}$ using a Veeco GEN II radio-frequency plasma-assisted molecular beam epitaxial growth system. Before loading into the MBE chamber, the $n^{+}-p$ Si substrate was cleaned with acetone and methanol to remove any organic contaminants. Subsequently, Si substrate was immersed in $10 \%$ buffered hydrofluoric acid to remove native oxide. The nanowires were formed spontaneously under nitrogen-rich conditions without using any external metal catalyst on the $\mathrm{Si}$ substrate. The growth conditions include a substrate temperature range of $670-675^{\circ} \mathrm{C}$, a Ga beam equivalent pressure (BEP) of $6 \times 10^{-8}$ torr, an In BEP of $5 \times 10^{-8}$ torr, Ge cell temperature range of $1050-1080^{\circ} \mathrm{C}, \mathrm{Mg}$ cell temperature range of $200-270$ ${ }^{\circ} \mathrm{C}$, nitrogen flow rate of 1 standard cubic centimeter per minute ( $\mathrm{sccm}$ ), and plasma forward power of $420 \mathrm{~W} . n^{+}$- InGaN buffer layer was initially grown on $n^{+}-\mathrm{Si}$ side for $1 \mathrm{~h}$. The TJ was subsequently grown on top of the $n^{+}$- InGaN buffer layer. It comprises of $p^{++}$-InGaN and $n^{++}$ InGaN, which is required to connect the two light absorbers. The top $p^{+}$-InGaN segment was then grown on top of the TJ. Previous studies showed that the indium incorporation may be highly nonuniform along the nanowire dimension ${ }^{2,3}$.

Structural characterizations. Room-temperature photoluminescence measurements of asgrown InGaN nanowires on $\mathrm{Si}$ were performed with a $\mathrm{He}-\mathrm{Cd} 325 \mathrm{~nm}$ laser as the excitation source. The photoluminescence emission was spectrally resolved by a SPEX spectrometer equipped with a photomultiplier tube (PMT) detector. SEM images were taken using Hitachi SU8000 at an accelerating voltage of $10 \mathrm{kV}$. The $\mathrm{X}$-ray diffraction spectrum for these samples was measured using a Rigaku SmartLab XRD. X-ray Photoelectron Spectroscopy measurements were conducted using Kratos Axis Ultra XPS with a monochromatic Al source with energy solution $\sim 0.5 \mathrm{eV}$. The 
binding energy of carbon $(284.8 \mathrm{eV})$ was used as a reference peak position for the measurements. The STEM measurements (Figures 3(b) and 3(c), and Supp. Info. Figure S4) were carried out using FEI Tecnai G2 F20 microscope operated at $200 \mathrm{keV}$. HAADF-STEM images were collected using a JEOL 3100R05 microscope with double Cs aberration corrected STEM (300 keV, 29 mrad), with EDX. The EELS maps (shown in Figure 3(d)) were obtained in a FEI Titan 80-300 doubleaberration corrected microscope equipped with a Gatan Quantum Spectrometer fitted with a direct electron detector (Gatan K2). The nanowires were mechanically transferred on the TEM copper grid.

Pt photo-deposition. The photocathode was put on a Teflon holder and placed in the bottom of a Pyrex chamber with a quartz window. Next, $20 \mu \mathrm{L}$ of $0.2 \mathrm{M}$ Chloroplatinic acid hydrate (99.9\%, Sigma Aldrich) was used as Pt precursor, and $10 \mathrm{~mL}$ of $\mathrm{CH}_{3} \mathrm{OH}$ (i.e., a hole scavenger) and $50 \mathrm{~mL}$ of Milli-Q $(\sim 2 \mathrm{M} \Omega)$ water were poured into the Pyrex chamber. The chamber was evacuated using a vacuum pump for $10 \mathrm{~min}$. Then the sample was irradiated using a $300 \mathrm{~W}$ xenon lamp (PerkinElmer, PE300BF) for $30 \mathrm{~min}$.

$\mathrm{Al}_{2} \mathrm{O}_{3}$ deposition. Before deposition of $\mathrm{Al}_{2} \mathrm{O}_{3}$ films, the $\mathrm{Pt} / p^{+}$-InGaN/TJ nanowires $/ n^{+}-p \mathrm{Si}$ photocathode was soaked in $37 \% \mathrm{HCl}$ solution for $\sim 2$ min which was subsequently rinsed with DI water and dried with $\mathrm{N}_{2}$ gun. $\mathrm{Al}_{2} \mathrm{O}_{3}$ thin films were deposited using Veeco/Ultratech/Cambridge Fiji G2 ALD tool. Trimethylaluminum (TMA) and deionized water were used as the aluminum precursor and reactant, respectively. After pre-treatment with $\mathrm{HCl}$ solution, the $\mathrm{Pt} / p^{+}-\mathrm{InGaN} / \mathrm{TJ} / n^{+}-\mathrm{InGaN}$ nanowires $/ n^{+}-p$ Si photocathode was placed inside the ALD deposition chamber at a substrate temperature of $200{ }^{\circ} \mathrm{C}$. Each ALD cycle consists of 900 sec preheat and $20 \mathrm{sec}$ deposition. The rate of deposition is $\sim 1 \AA$ Acycle. The process was repeated for 20 cycles to achieve a thin film. The sample, after ALD deposition, was annealed in a rapid 
thermal annealing tool for 2 min under Ar gas flow. The optimization of ALD deposition temperature, and annealing temperature, in terms of PEC performance, are discussed in Supp. Info. Figure S8.

Electrode preparation. The $\mathrm{Al}_{2} \mathrm{O}_{3} / \mathrm{Pt} / p^{+}$-InGaN/TJ nanowires $/ n^{+}-p$ Si photocathode was diced into smaller pieces using a diamond pen. The back contact was made by using Ga-In eutectic paste on the backside of the sample and subsequently connecting a $\mathrm{Cu}$-wire on the ohmic contact by applying the silver paste. The electrical connection was then encapsulated by using epoxy by covering the sample except exposing the nanowires to eliminate any leakage currents. As shown in Figure S1, the epoxy (Loctite EA 615) was found to be non-transparent for different thicknesses. Due to the non-transparent nature of the epoxy, light reflections from the epoxy near the perimeter of the sample will not significantly affect the surface area calculations.

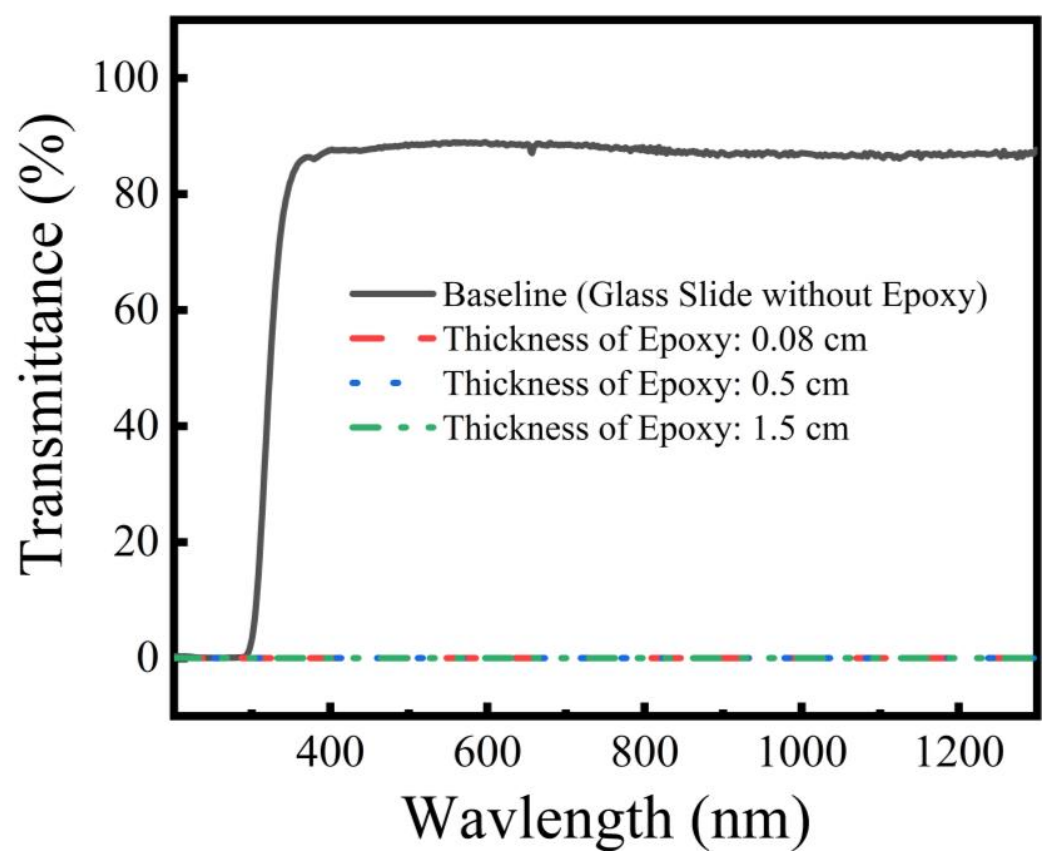

Figure S1. Transmission measurements for different epoxy thicknesses and baseline glass slide (without epoxy). 
Surface Area Calculation. The exposed photoelectrode surface area was determined by using an optical scanner (Figure S1(a)) and the open-source software ImageJ. As shown in Figure S1(b), the edges of the epoxy were used as a borderline, and the area of this sample (red region in Figure S1(b)) calculated by using the software is $0.025 \mathrm{~cm}^{2}$. The sample areas used in this work were between $0.01-0.03 \mathrm{~cm}^{2}$.

(a)

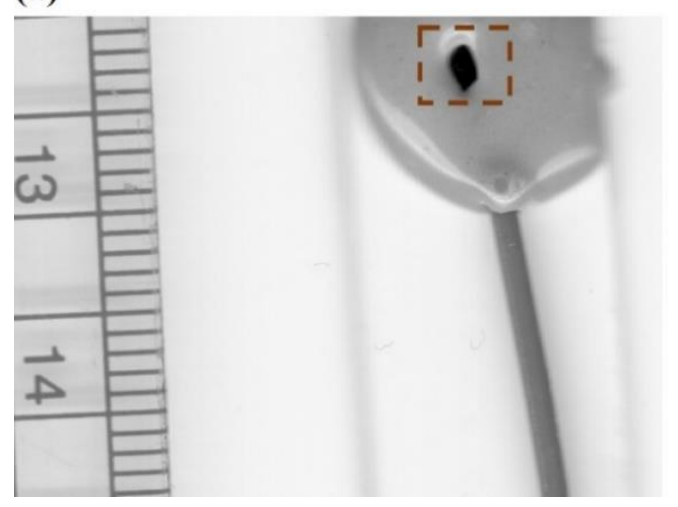

(b)

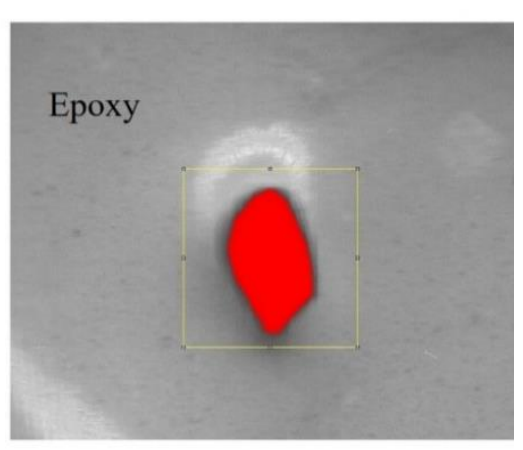

Figure S2. (a) Optical scanner image of the double junction photoelectrode with a standard scale as a reference object. (b) ImageJ processed picture showing the electrode area (red color region within the yellow boundaries) from the brown dashed box in Figure S1(a). The edges of the epoxy serve as borders for surface area calculation. The sample area of the electrode, in Figure S1(a), is $0.025 \mathrm{~cm}^{2}$.

IrO $\mathrm{x}_{\mathrm{x}}$ counter electrode preparation. $\mathrm{IrO}_{\mathrm{x}}$ counter electrodes were prepared on two substrates, including Ti and FTO. An iridium chloride precursor solution was spin-coated on the substrate, which was then followed by annealing at $400{ }^{\circ} \mathrm{C}$ for $30 \mathrm{~min}$ as mentioned elsewhere ${ }^{4}$. After deposition, the substrate is mounted on $\mathrm{Cu}$ wire and encapsulated with epoxy on a glass rod. The dimensions of the electrodes are $3.5 \mathrm{~cm} \times 0.8 \mathrm{~cm}$. 
Photoelectrochemical reactions. The PEC reaction was conducted in a $0.5 \mathrm{M} \mathrm{H}_{2} \mathrm{SO}_{4}$ solution using $\mathrm{Al}_{2} \mathrm{O}_{3} / \mathrm{Pt} / p^{+}-\mathrm{InGaN} / \mathrm{TJ}$ nanowires on $n^{+}-p \mathrm{Si}$ photocathode, silver chloride electrode $(\mathrm{Ag} / \mathrm{AgCl})$, and $\mathrm{IrO}_{\mathrm{x}}$ as the working, reference, and counter electrode, respectively. A solar simulator (Newport Oriel) with an AM1.5 G filter was used as the light source, and the light intensity was calibrated to $100 \mathrm{~mW} / \mathrm{cm}^{2}$ by using a GaInP 2 (bandgap $\sim 1.8 \mathrm{eV}$ ) reference cell. The conversion of the $\mathrm{Ag} / \mathrm{AgCl}$ reference potential to a reversible hydrogen electrode (RHE) is calculated using Eqn. 1,

$E_{(R H E)}=E_{A g / A g C l}+E_{A g / A g C l}^{o}+0.059 \times p H$

where $E_{A g / A g C l}^{o}$ is $0.197 \mathrm{~V}$, and $\mathrm{pH}$ of the electrolyte is nearly zero. The ABPE of the photocathode is derived using Eqn. 2,

$\eta(\%)=\frac{\mathrm{J}\left(V_{R H E}-E_{r e v}^{0}\right)}{P_{\text {in }}} \times 100$

where $J$ is the photocurrent density, $E_{r e v}^{0}=0 \mathrm{~V} v s$. RHE, $V_{R H E}$ is the applied bias $v s$. RHE, and $P_{\text {in }}$ is the power of the incident light (i.e., $100 \mathrm{~mW} / \mathrm{cm}^{2}$ ).

The $\mathrm{STH}$ of $\mathrm{Al}_{2} \mathrm{O}_{3} / \mathrm{Pt} / p^{+}$-InGaN/TJ nanowires on $n^{+}-p$ Si photocathode, which is measured in the two-electrode configuration, is calculated using Eqn. (3),

$S T H(\%)=\left[\frac{\mid J \text { SSC }\left(\mathrm{mA.cm}^{-2}\right) \mid \times 1.23(\mathrm{~V}) \times \eta_{(\text {Faraday })}}{P_{\text {tot }}\left(\mathrm{mW} . \mathrm{cm}^{-2}\right)}\right] \times 100$

where $J_{S C}$ is the short circuit photocurrent density at $0 \mathrm{~V} v s . \mathrm{IrO}_{\mathrm{x}}, P_{\text {tot }}$ is $\mathrm{AM} 1.5 \mathrm{G}$ one sun illumination $\left(100 \mathrm{~mW} / \mathrm{cm}^{2}\right) ; \eta_{\text {(Faraday) }}$ is the Faradaic efficiency for $\mathrm{H}_{2}$ production.

Impedance measurements. For impedance studies, AC perturbations of amplitude $10 \mathrm{mV}$ are superimposed with frequency in the range of $0.1 \mathrm{~Hz}-1 \mathrm{MHz}$. We have performed EIS measurements in $0.5 \mathrm{M} \mathrm{H}_{2} \mathrm{SO}_{4}$ under $\mathrm{AM} 1.5 \mathrm{G}$ one-sun illumination. For three-electrode and twoelectrode EIS measurements, the applied biases are $1.2 \mathrm{~V} v s$. RHE and $0 \mathrm{~V} v s . \mathrm{IrO}_{\mathrm{x}}$, respectively. 
Equivalent circuit modeling and curve fitting for the Nyquist plots were done by using EC lab software (BioLogic Science Instruments), which are mentioned elsewhere ${ }^{1}$. Mott-Schottky measurements are done at $1 \mathrm{kHz}$ by sweeping the applied bias $v s$. RHE from $1.9 \mathrm{~V}$ to $2.4 \mathrm{~V}$ with the above-mentioned AC perturbation amplitude.

$\mathbf{H}_{2}$ evolution experiments. The $\eta_{\text {(Faraday) }}$ for the $\mathrm{H}_{2}$ evolution measurements were calculated by using Eqn. 5, which is the ratio of average experimental (red dots in Figure 6(a)) and theoretically calculated (black dots in Figure 6(b)) $\mathrm{H}_{2}$ production.

$$
\eta_{(\text {Faraday })}(\%)=\frac{2 \times n_{H_{2}}\left(t=T_{0}\right)[\mathrm{mol}] \times F}{\int_{0}^{T_{0}} I[A] . d t[s]} \times 100
$$

where $I$ is the measured photocurrent, $F$ is Faradaic constant $(96485 \mathrm{C} / \mathrm{mol})$ and $n_{\mathrm{H}_{2}}$ is the total amount of $\mathrm{H}_{2}$ produced for a time duration $T_{0} . \mathrm{H}_{2}$ was detected by gas chromatography (GC, Shimadzu GC-8A) equipped with a thermal conducting detector (TCD). 
Table T1. Main parameters used for the SCAPS (Solar Cell Capacitance Simulator) simulation of an ideal $\operatorname{In}_{0.46} \mathrm{Ga}_{0.54} \mathrm{~N} / \mathrm{Si}$ tandem device.

\begin{tabular}{|c|c|c|c|c|c|c|c|}
\hline Subcell & Top & & & & Bottom & & \\
\hline Material & p-InGaN & $\mathbf{p}^{++}-\operatorname{InGaN}$ & $\mathrm{n}^{++}-\operatorname{InGaN}$ & n-InGaN & $\mathrm{n}^{+}-\mathrm{Si}$ & $\mathbf{p}-\mathbf{S i}$ & $\mathbf{p}^{+}-\mathbf{S i}$ \\
\hline Thickness (um) & 0.5 & 0.065 & 0.04 & 0.25 & 0.45 & 300 & 0.5 \\
\hline Bandgap (eV) & 1.8 & 1.8 & 1.8 & 1.8 & 1.12 & 1.12 & 1.12 \\
\hline electron affinity (eV) & 4.50 & 4.40 & 4. 45 & 4.46 & 4 & 4 & 4 \\
\hline Dielectric constant & 9 & 9 & 9 & 9 & 11 & 11 & 11 \\
\hline CB DOS $\left(\mathrm{cm}^{-3}\right)$ & $4.00 E+18$ & $2.50 \mathrm{E}+18$ & $2.50 \mathrm{E}+18$ & $2.50 \mathrm{E}+18$ & $2.80 E+19$ & $2.80 E+19$ & $2.80 E+19$ \\
\hline CV DOS $\left(\mathrm{cm}^{-3}\right)$ & $3.00 \mathrm{E}+17$ & $3.00 E+17$ & $3.00 \mathrm{E}+17$ & $3.00 E+17$ & $1.00 E+19$ & $1.00 \mathrm{E}+19$ & $1.00 \mathrm{E}+19$ \\
\hline Hole mobility $\left(\mathrm{cm}^{2} / \mathrm{s}\right)$ & $1.00 E+03$ & $1.00 \mathrm{E}+03$ & $1.00 \mathrm{E}+03$ & $1.00 \mathrm{E}+03$ & $1.50 \mathrm{E}+03$ & $1.50 E+03$ & $1.50 \mathrm{E}+03$ \\
\hline electron mobility $\left(\mathrm{cm}^{2} / \mathrm{s}\right)$ & $2.50 E+02$ & $2.50 E+02$ & $2.50 \mathrm{E}+02$ & $2.50 E+02$ & $4.50 \mathrm{E}+02$ & $4.50 E+02$ & $4.50 E+02$ \\
\hline $\begin{array}{l}\text { shallow donor/acceptor } \\
\text { density } N_{D} / N_{A}\left(\mathrm{~cm}^{-3}\right)\end{array}$ & $1.00 \mathrm{E}+17$ & $5.00 \mathrm{E}+18$ & $5.00 \mathrm{E}+18$ & $2.00 E+18$ & $5.00 \mathrm{E}+20$ & $1.00 E+15$ & $1.50 \mathrm{E}+20$ \\
\hline
\end{tabular}

The simulation of the $J-V$ curves of double-junction tandem devices was performed by combining SCAPS software ${ }^{5}$ and a customized Igor Pro program. SCAPS was used to simulate the photovoltaic performance of individual single-junction devices, including a $p^{+}$-InGaN top subcell and a $n^{+}-\mathrm{InGaN} / \mathrm{Si}$ bottom subcell (see Figure 1(c)). The main parameters used for simulating an ideal tandem device are tabulated in Table T1. The tunneling junction was treated as an Ohmic contact for both the top and bottom cells. After the simulation of individual subcells, the customized Igor Pro code was employed to calculate the current match conditions for the monolithically connected tandem devices by using an interpolation function and generate $J-V$ curves for tandem devices. 
Table T2. Details of single and double junction photocathodes used in the PEC experiments.

Samples B and C are from region 3 in Figure S13 (see Supp. Info. Section S2).

\begin{tabular}{|c|c|c|c|c|c|c|}
\hline \multirow{2}{*}{ Photocathode } & \multirow{2}{*}{$\begin{array}{c}\text { Sample } \\
\text { Designation }\end{array}$} & \multirow{2}{*}{ Configuration } & \multicolumn{2}{|c|}{$\begin{array}{l}\text { MBE Growth } \\
\text { Conditions } \\
\end{array}$} & \multirow{2}{*}{ Pt Co-catalyst } & \multirow{2}{*}{$\begin{array}{c}\mathrm{Al}_{2} \mathrm{O}_{3} \\
\text { passivation } \\
\text { layer }\end{array}$} \\
\hline & & & $\begin{array}{c}\text { Tunnel } \\
\text { Junction }\end{array}$ & $\begin{array}{l}\text { Top } p^{+}- \\
\text {InGaN }\end{array}$ & & \\
\hline $\begin{array}{c}\mathrm{Pt} / n^{+}-\mathrm{InGaN} \\
\text { nanowires } / n^{+}-p \mathrm{Si}\end{array}$ & Sample A & $\begin{array}{l}\text { Single- } \\
\text { junction }\end{array}$ & No & No & Yes & No \\
\hline $\begin{array}{c}\mathrm{Al}_{2} \mathrm{O}_{3} / \mathrm{Pt} / p^{+}-\operatorname{InGaN} / \mathrm{TJ} \\
\text { nanowires } / n^{+}-p \mathrm{Si}\end{array}$ & Sample B & $\begin{array}{l}\text { Double- } \\
\text { junction }\end{array}$ & Yes & Yes & Yes & Yes \\
\hline $\begin{array}{c}\mathrm{Pt} / p^{+}-\operatorname{InGaN} / \mathrm{TJ} \\
\text { nanowires } / n^{+}-p \mathrm{Si}\end{array}$ & Sample C & $\begin{array}{l}\text { Double- } \\
\text { junction }\end{array}$ & Yes & Yes & Yes & No \\
\hline
\end{tabular}




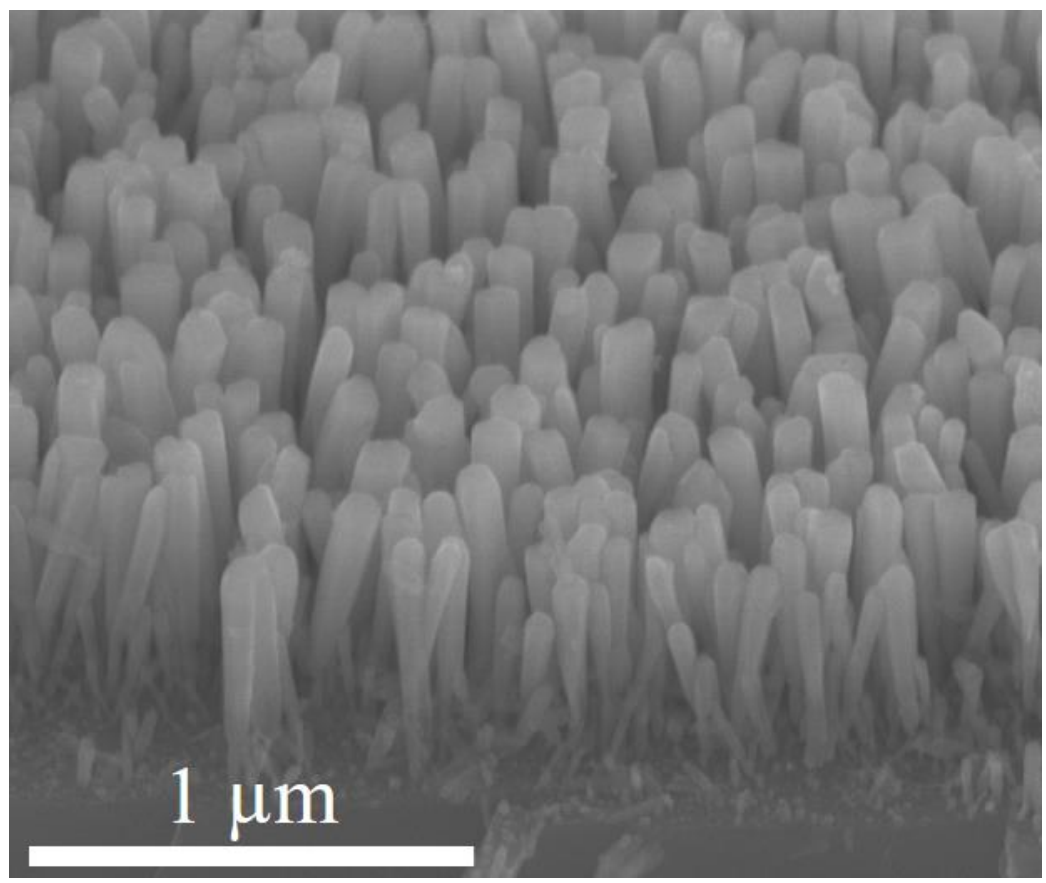

Figure S3. $45^{\circ}$ tilt SEM image of InGaN/Si double junction nanowires after surface modifications, i.e., Pt nanoparticles photo-deposition and $\mathrm{Al}_{2} \mathrm{O}_{3}$ deposition on pristine sample. 
(a)

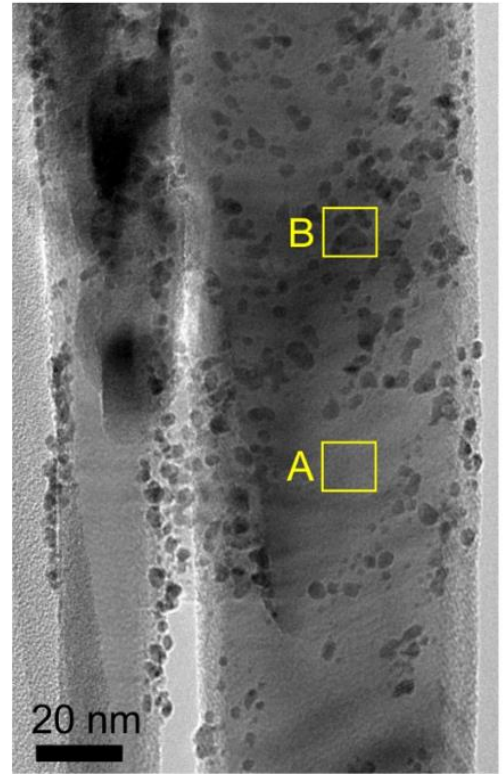

(b)

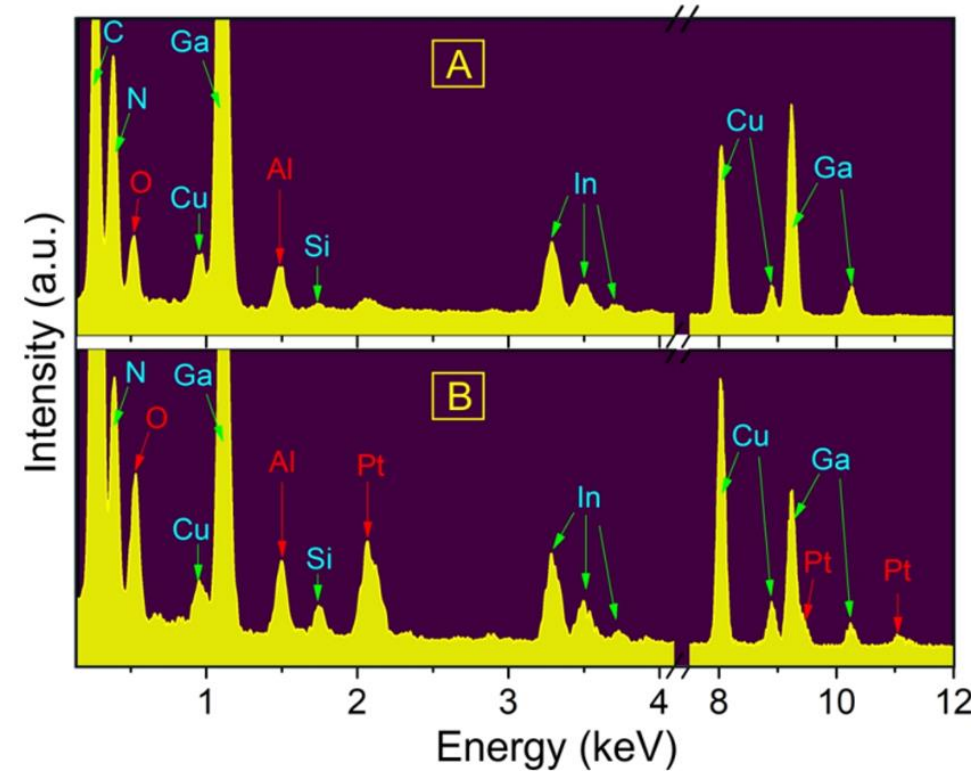

Figure S4. (a) STEM image showing Pt nanoparticles and $\mathrm{Al}_{2} \mathrm{O}_{3}$ layer along $\mathrm{InGaN}$ nanowire. (b) EDS elemental mapping of $\mathrm{A}$ and $\mathrm{B}$ regions shown in Figure S3(a). The nanowire and Pt nanoparticles are covered by a thin $\mathrm{Al}_{2} \mathrm{O}_{3}$ layer. 


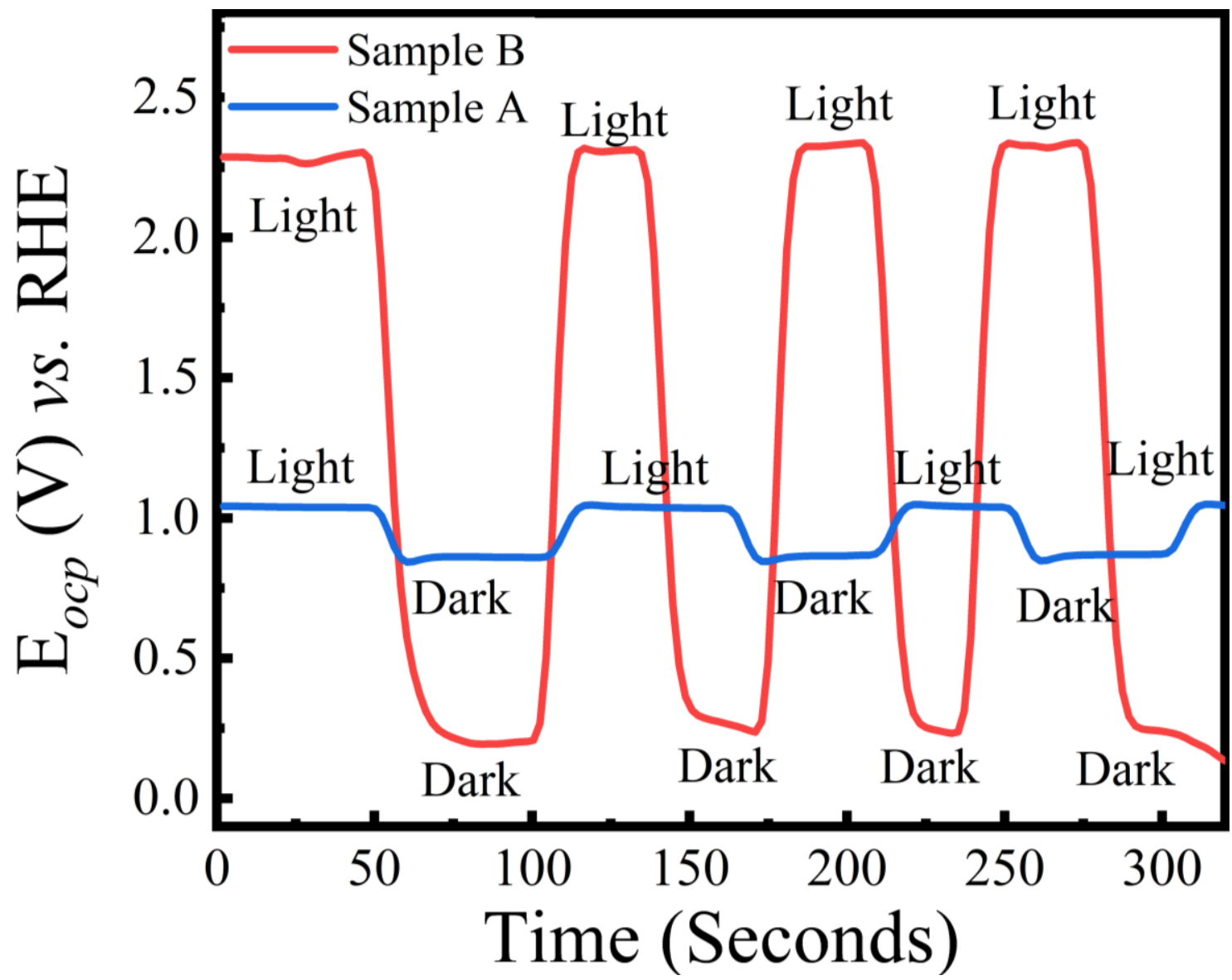

Figure S5. OCP vs. RHE for Sample B (red curve) and Sample A (blue curve) (see Supp. Info. Table T2) under chopped AM 1.5G one-sun illumination in $0.5 \mathrm{M} \mathrm{H}_{2} \mathrm{SO}_{4}$. 


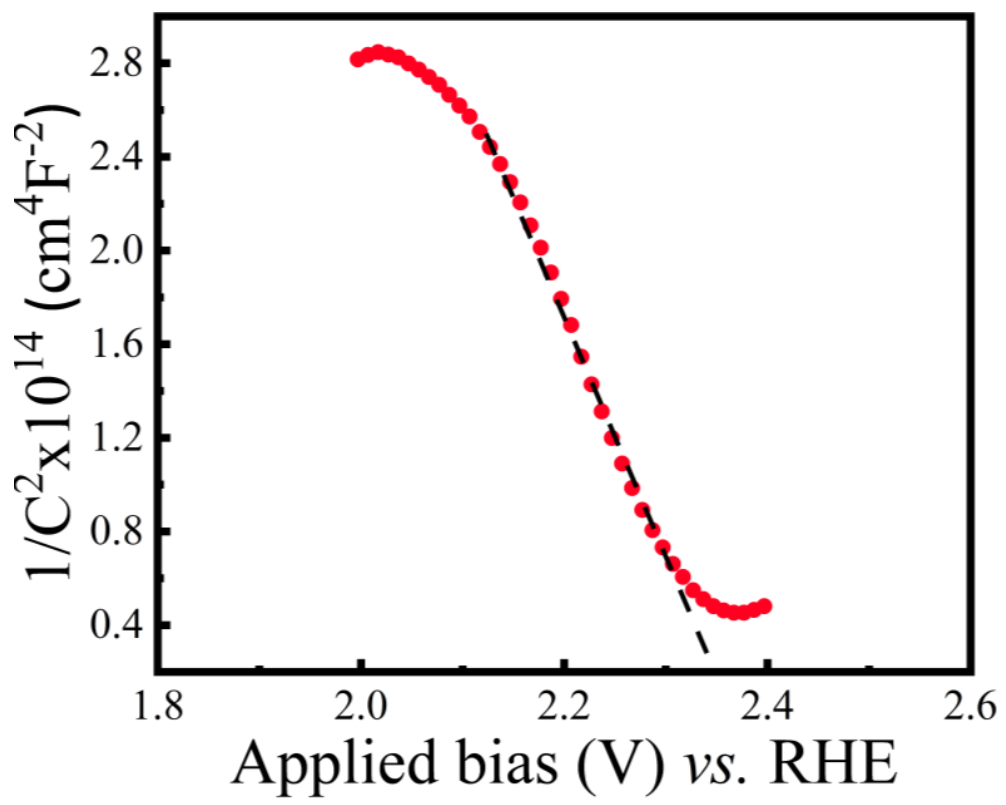

Figure S6. Mott-Schottky plot of Sample B (see Supp. Info. Table T2) under dark condition in $0.5 \mathrm{M} \mathrm{H}_{2} \mathrm{SO}_{4}$. 
(a)

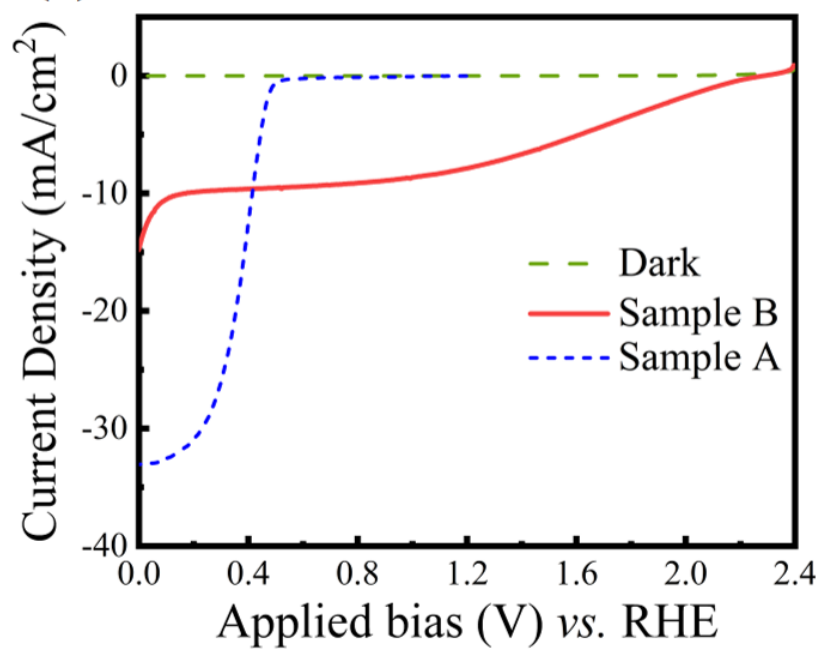

(b)

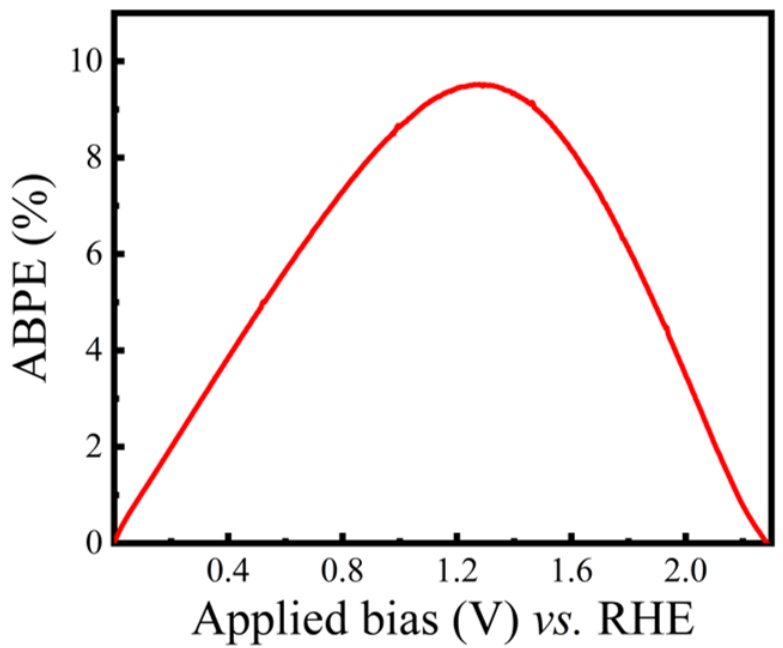

Figure S7. (a) LSV of Samples A (dotted blue curve) and B (red curve) under AM1.5G one-sun illumination and dark (dashed green curve) in $0.5 \mathrm{M} \mathrm{H}_{2} \mathrm{SO}_{4}$ scanned between $2.4 \mathrm{~V}$ and $0 \mathrm{~V} v s$. RHE. As shown in this figure, the maximum photocurrent density for Sample B is $\sim 16 \mathrm{~mA} / \mathrm{cm}^{2}$ at $0 \mathrm{~V} v s$. RHE. The deviation from theoretical photocurrent density limit ${ }^{6}$ is due to the additional current coming from the bottom $n^{+}-\mathrm{InGaN} / n^{+}-p$ Si subcell. The Pt nanoparticles on the $n^{+}-\mathrm{InGaN}$ may contribute to the extraction of photo-generated electrons from the bottom Si cell for proton reduction ${ }^{7}$. Therefore, at lower biases ( $<0 \mathrm{~V} v s$. RHE), the bottom Si cell provides additional photocurrent density along with top $p^{+}$-InGaN segment which thereby increases the overall photocurrent density of the photocathode. (b) ABPE of Sample B (see Supp. Info. Table T2) under AM $1.5 \mathrm{G}$ one-sun illumination in $0.5 \mathrm{M} \mathrm{H}_{2} \mathrm{SO}_{4}$. 
(a)

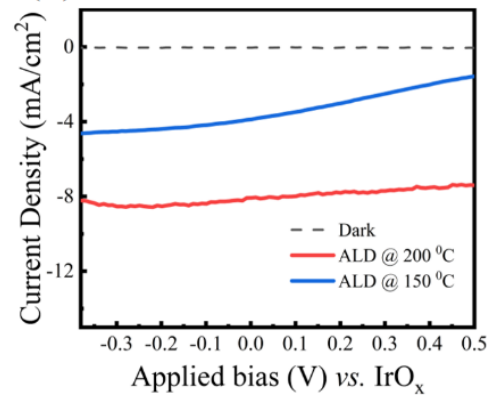

(b)

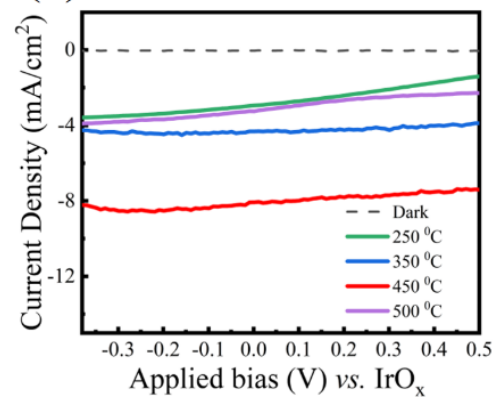

(c)

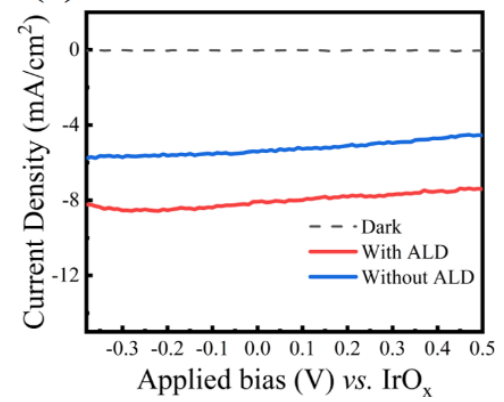

Figure S8. Two-electrode $J$-V characteristics of $\mathrm{Al}_{2} \mathrm{O}_{3}$ (thickness of $\sim 2 \mathrm{~nm}$ ) $/ \mathrm{Pt} / p^{+}-\mathrm{InGaN} / \mathrm{TJ}$ nanowires on $n^{+}$- $p$ Si photocathode in $0.5 \mathrm{M} \mathrm{H}_{2} \mathrm{SO}_{4}$ under $\mathrm{AM} 1.5 \mathrm{G}$ one-sun illumination for (a) different $\mathrm{Al}_{2} \mathrm{O}_{3}$ deposition temperatures: $150{ }^{\circ} \mathrm{C}$, and $200{ }^{\circ} \mathrm{C}$; (b) different rapid thermal annealing temperatures: $250{ }^{\circ} \mathrm{C}, 350{ }^{\circ} \mathrm{C}, 450{ }^{\circ} \mathrm{C}$, and $500{ }^{\circ} \mathrm{C}$. (c) LSV comparison of the sample with optimized ALD/annealing conditions (red curve) and without ALD (blue curve) under AM1.5G one-sun illumination in $0.5 \mathrm{M} \mathrm{H}_{2} \mathrm{SO}_{4}$. Based on these measurements the best optimized condition for the photocathode consists of $2 \mathrm{~nm}$ thin $\mathrm{Al}_{2} \mathrm{O}_{3}$ film deposited at $200{ }^{\circ} \mathrm{C}$ and subsequently annealed at $450{ }^{\circ} \mathrm{C}$ for $2 \mathrm{~min}$. 


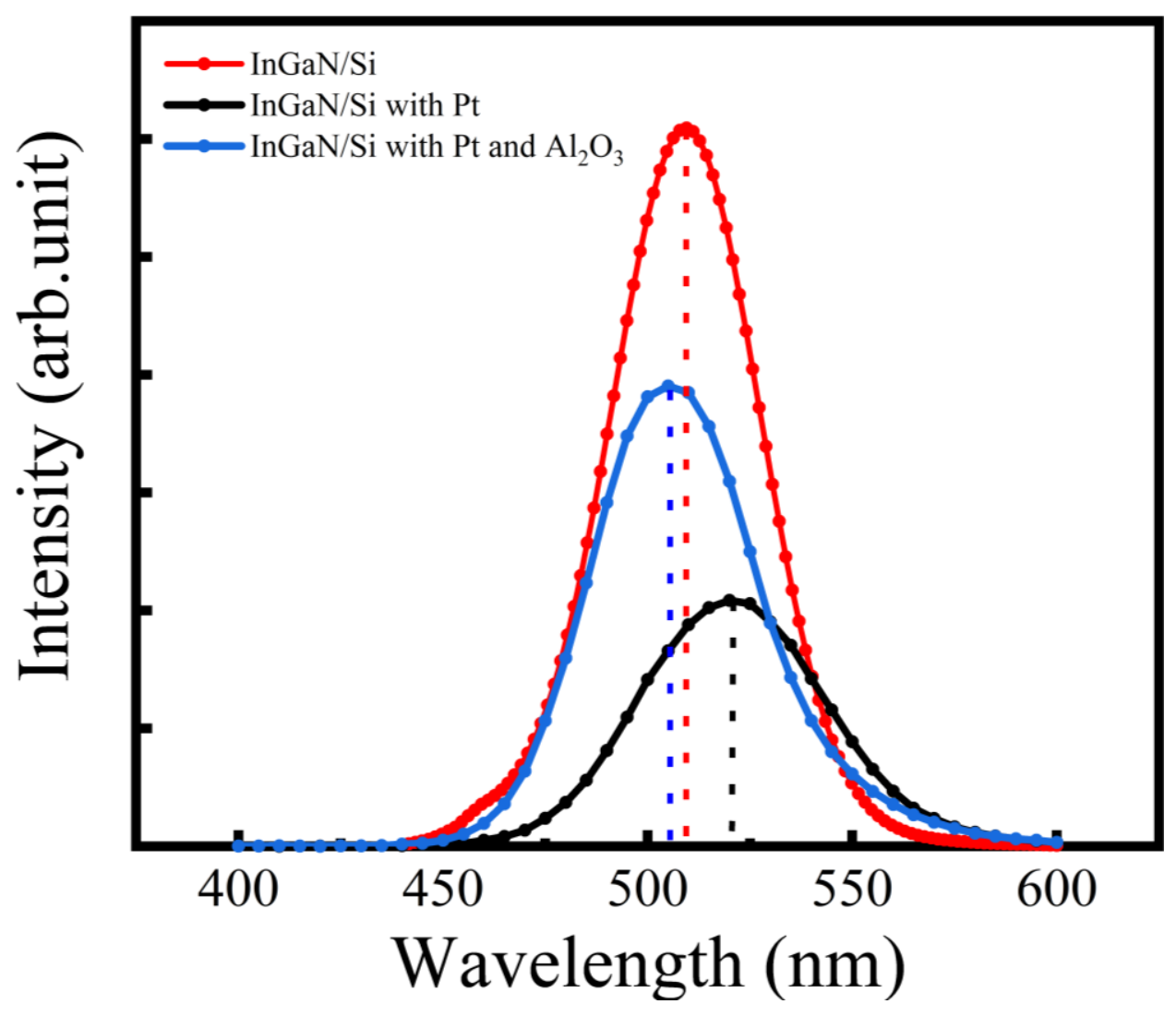

Figure S9. Room-temperature photoluminescence spectrum of pristine $p^{+}$-InGaN nanowires (red curve), Pt modified $p^{+}$-InGaN nanowires (black curve), and Pt plus $\mathrm{Al}_{2} \mathrm{O}_{3}$ modified $p^{+}$-InGaN nanowires (blue curve). The red, black, and blue dotted lines show the peak positions for the pristine, with $\mathrm{Pt}$, and with $\mathrm{Pt} / \mathrm{Al}_{2} \mathrm{O}_{3}$ are $\sim 510 \mathrm{~nm}, \sim 520 \mathrm{~nm}$ and $\sim 505 \mathrm{~nm}$, respectively. The shift in peak positions for sample with $\mathrm{Pt}$ and sample with $\mathrm{Pt} / \mathrm{Al}_{2} \mathrm{O}_{3}$ when compared to pristine sample is due to the relative variation of Indium incorporation in the $\mathrm{InGaN}$ nanowires. 


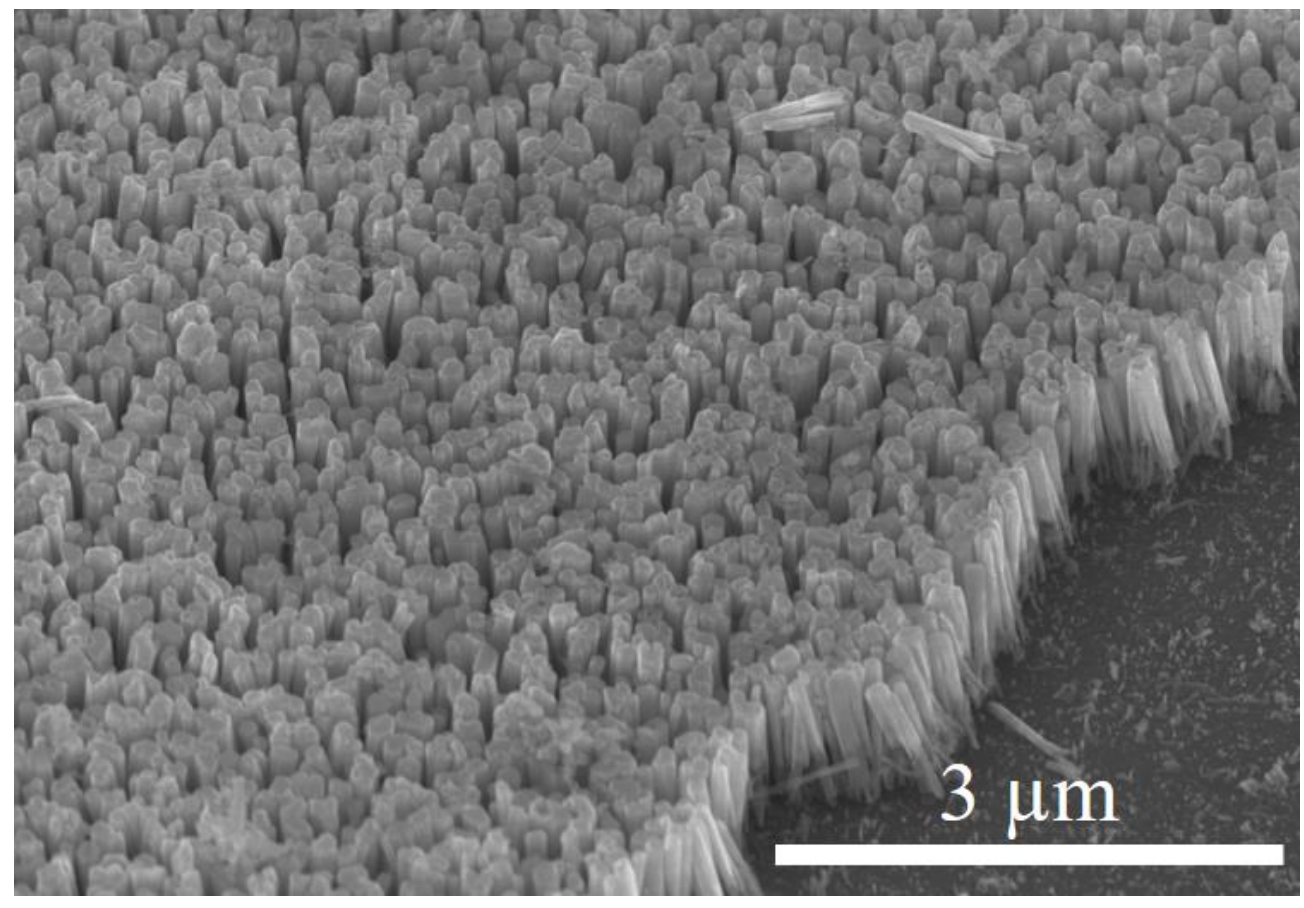

Figure S10. $45^{\circ}$ tilt SEM of $\mathrm{Al}_{2} \mathrm{O}_{3} / \mathrm{Pt} / p^{+}-\mathrm{InGaN} / \mathrm{TJ}$ nanowires on $n^{+}-p$ Si photocathode after 100 h stability experiments. For SEM measurement of the sample (after reaction), the wafer had to be mechanically removed from the epoxy used in sample preparation (see Supp. Info. Section S1). During this removal, the tweezers make some scratches on the wafer. This unintentional scratching removes some nanowires from certain regions of Si substrate as shown in Figure S10. 


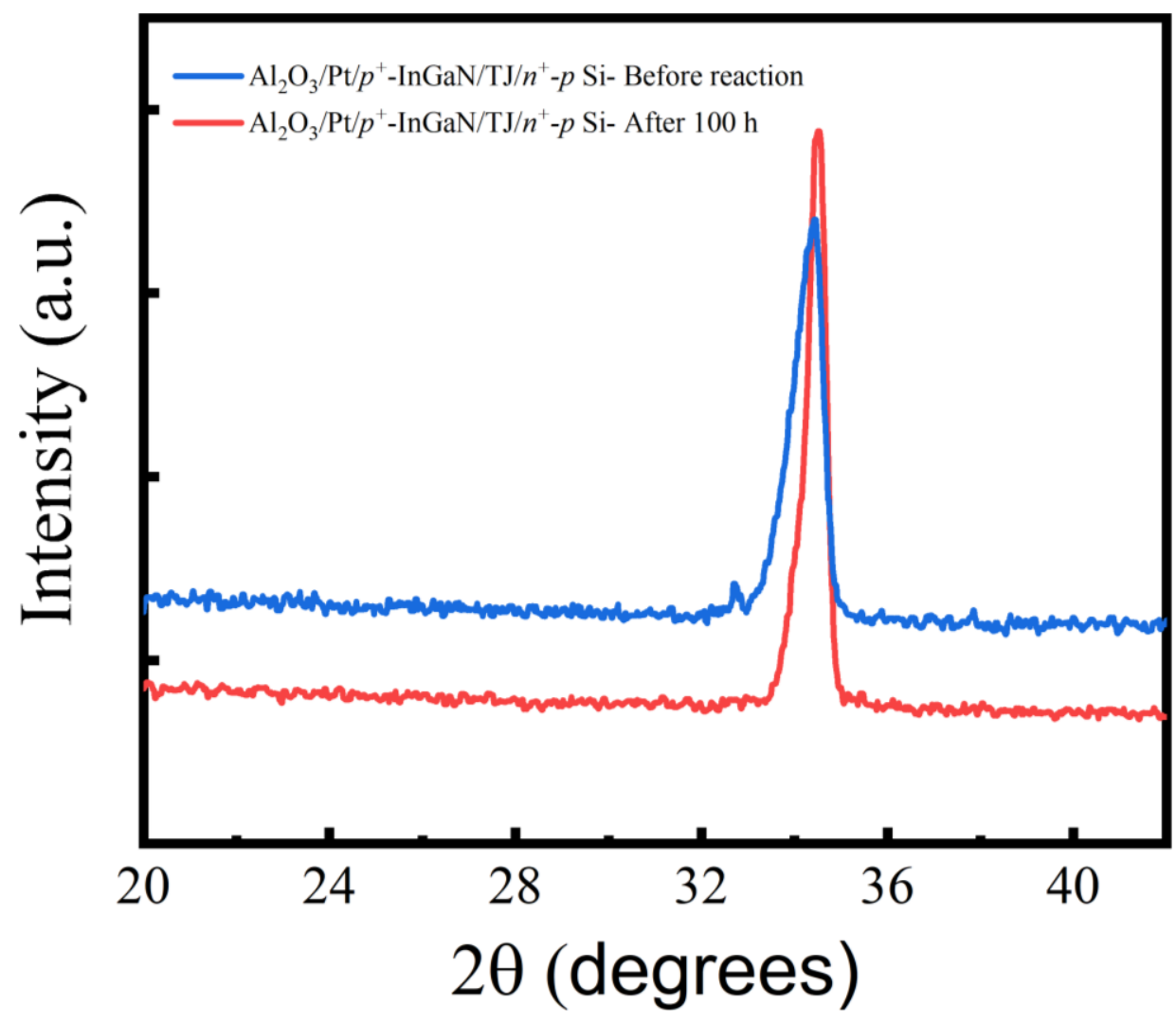

Figure S11. X-ray diffraction measurement of $\mathrm{Al}_{2} \mathrm{O}_{3} / \mathrm{Pt} / p^{+}-\mathrm{InGaN} / \mathrm{TJ}$ nanowires on $n^{+}-p \mathrm{Si}$ photocathode before (blue color) and after $100 \mathrm{~h}$ (red color) PEC stability reaction. The peak position is $\sim 34.4^{\circ}$ for both samples. 


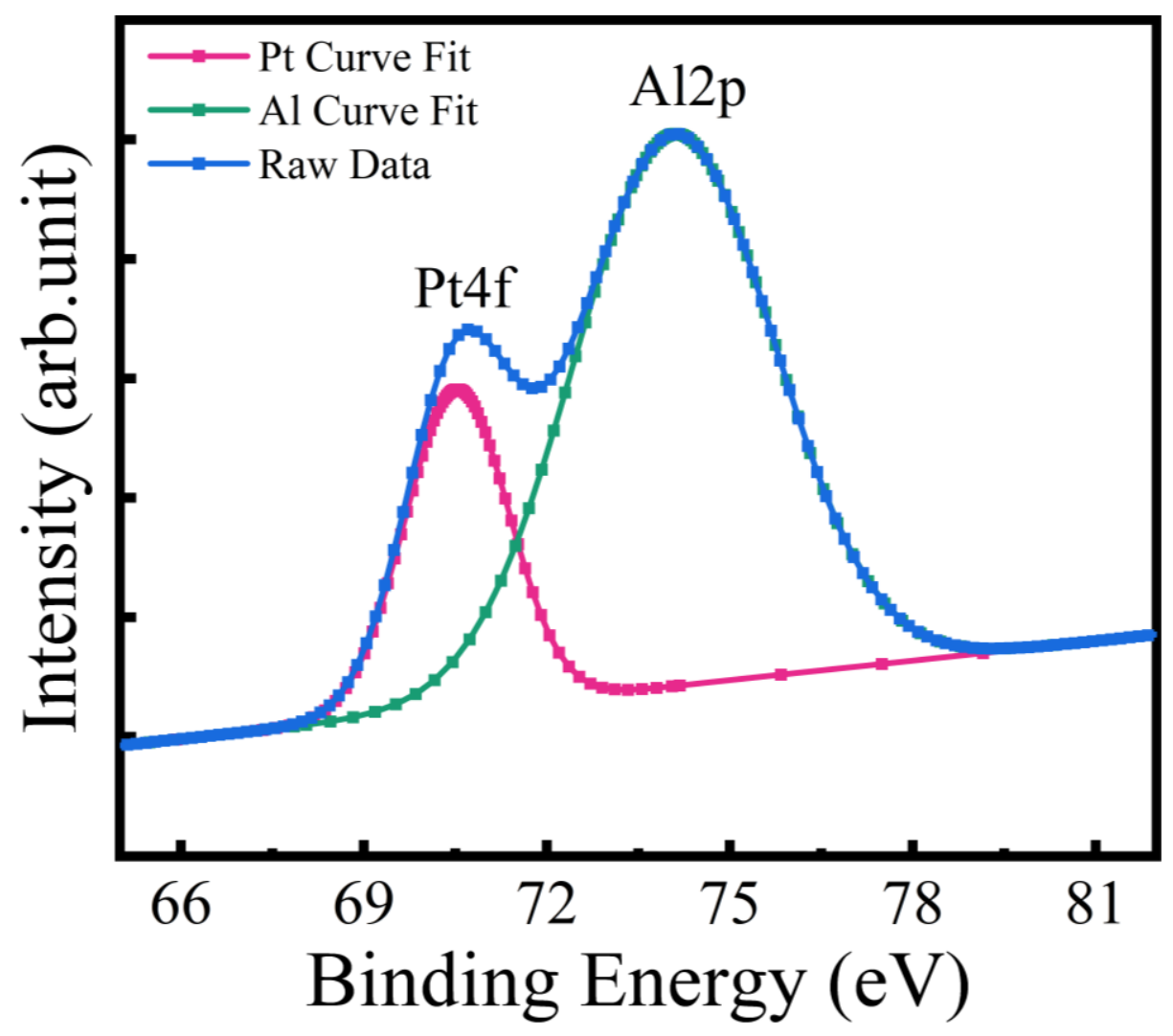

Figure S12. XPS diffraction measurement of $\mathrm{Al}_{2} \mathrm{O}_{3} / \mathrm{Pt} / p^{+}-\mathrm{InGaN} / \mathrm{TJ}$ nanowires on $n^{+}-p \mathrm{Si}$ photocathode after $100 \mathrm{~h}$ PEC stability reaction. The blue curve is the raw data. The pink and green curves are the curve fittings for Pt4f and Al2p respectively. 


\section{Section S2. Indium variation and sample size}

The nanowires were grown using spontaneous catalyst-free MBE growth technique under nitrogen-rich conditions ${ }^{7-9}$. The MBE substrate heater has a temperature gradient as shown by the arrow in Figure 13(a), which leads to different band gaps (varied Indium incorporation) from one region to another within the MBE grown wafer. Figure S13(b) shows the PL peak positions for three different regions (see Figure S13(a)) across the InGaN/Si sample. Due to the low sticking coefficient of Indium atoms ${ }^{10}$, at lower substrate temperatures more Indium gets incorporated which gives rise to lower bandgap (or longer wavelength) ${ }^{3,10}$. The MBE growth parameters were tuned by growing the InGaN nanowires at a relatively high temperature (see Supp. Info. Section S1) with high Indium flux to obtain good crystalline quality InGaN nanowires with reduced phase separation and less surface defects ${ }^{2,11}$ across the wafer. Regions 2 and 3 (see Figure 13(a)) have higher Indium incorporation.

(a)

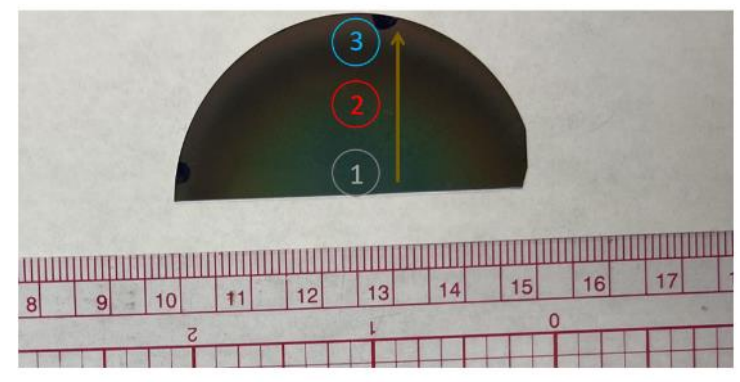

(b)

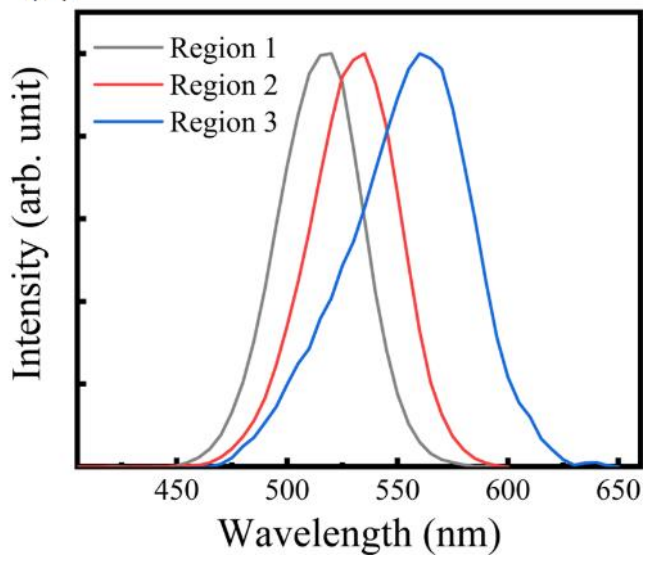

Figure S13. (a) Optical image of InGaN nanowire arrays grown on Si $p$ - $n$ wafer. This image shows half of the two-inch wafer with different regions marked in gray (region 1), red (region 2), and blue (region 3). The brown arrow indicates the temperature gradient of the MBE substrate heater from high (region 1) to relatively low (region 3) temperature in the wafer. (b) PL of the three 
regions measured at room temperature. The PL peak positions are region $1 \sim 515 \mathrm{~nm}$, region $2 \sim$ $535 \mathrm{~nm}$, and region $3 \sim 560 \mathrm{~nm}$. The best performing samples are approximately near region 3 .

Furthermore, this temperature gradient gives rise to uneven nanowire morphology as well as variations in $\mathrm{Mg}$ dopant incorporation, which was discussed in our previous reports ${ }^{2,3,12}$. It is noted that due to this unevenness, there will be variations of light trapping, as well as shadowing effect in epitaxy, which will vary the doping concentration ${ }^{2}$ and potentially impact the tunnel junction within the nanowires. Since we use the thermal diffusion technique for Si solar cell fabrication ${ }^{1}$, the sheet resistance for both p-type (30-60 $\Omega$-sq) and n-type (8-20 $\Omega$-sq) doped sides varies across the different regions of the Si wafer and thereby limit the sample size within 0.05 $0.08 \mathrm{~cm}^{2}$ for good uniformity and photovoltaic performance. Therefore, the cumulative effect of all these factors leads to performance variations across the entire wafer. From the aforementioned factors and PEC measurements, it is observed that the smaller area $\left(<0.04 \mathrm{~cm}^{2}\right)$ photoelectrodes performed better than photoelectrodes with size $\left(>0.1 \mathrm{~cm}^{2}\right)$. Another possible reason for a lower than expected performance, apart from the above-discussed reasons, of larger size samples, is due to the longer ion transport pathway around the sample, which could create more electrolyte resistance losses within the PEC cell ${ }^{13}$. From previous reports ${ }^{14-16}$, the high-efficiency samples were relatively small $\left(\leq 0.1 \mathrm{~cm}^{2}\right)$ samples, and larger samples showed poor performance due to overpotential losses and significant defects ${ }^{13}$. In future work, we would address these issues related to sample uniformity by utilizing selective area growth technique ${ }^{17,18}$ and commercial $\mathrm{Si}$ solar cells to grow InGaN nanowires with uniform morphology and nearly constant indium incorporation. 


\section{References}

1. Vanka, S.; Arca, E.; Cheng, S.; Sun, K.; Botton, G. A.; Teeter, G.; Mi, Z. High Efficiency Si Photocathode Protected by Multifunctional GaN Nanostructures. Nano Lett. 2018, 18, (10), $6530-6537$.

2. Wang, Y.; Wu, Y.; Schwartz, J.; Sung, S. H.; Hovden, R.; Mi, Z. A Single-Junction Cathodic Approach for Stable Unassisted Solar Water Splitting. Joule 2019, 3, (10), 2444-2456.

3. Kibria, M. G.; Chowdhury, F. A.; Zhao, S.; AlOtaibi, B.; Trudeau, M. L.; Guo, H.; Mi, Z. Visible light-driven efficient overall water splitting using $p$-type metal-nitride nanowire arrays. Nat. Commun. 2015, 6, 6797.

4. Spurgeon, J. M.; Velazquez, J. M.; McDowell, M. T. Improving $\mathrm{O}_{2}$ production of $\mathrm{WO}_{3}$ photoanodes with $\mathrm{IrO}_{2}$ in acidic aqueous electrolyte. Phys. Chem. Chem. Phys. 2014, 16, (8), 362331.

5. Burgelman, M.; Nollet, P.; Degrave, S. Modelling polycrystalline semiconductor solar cells. Thin Solid Films 2000, 361-362, 527-532.

6. Chen, Z.; Jaramillo, T. F.; Deutsch, T. G.; Kleiman-Shwarsctein, A.; Forman, A. J.; Gaillard, N.; Garland, R.; Takanabe, K.; Heske, C.; Sunkara, M.; McFarland, E. W.; Domen, K.; Miller, E. L.; Turner, J. A.; Dinh, H. N. Accelerating materials development for photoelectrochemical hydrogen production: Standards for methods, definitions, and reporting protocols. J. Mater. Res. 2011, 25, (01), 3-16.

7. Fan, S.; AlOtaibi, B.; Woo, S. Y.; Wang, Y.; Botton, G. A.; Mi, Z. High efficiency solarto-hydrogen conversion on a monolithically integrated InGaN/GaN/Si adaptive tunnel junction photocathode. Nano Lett. 2015, 15, (4), 2721-6. 
8. Kibria, M. G.; Nguyen, H. P. T.; Cui, K.; Zhao, S.; Liu, D.; Guo, H.; Trudeau, M. L.; Paradis, S.; Hakima, A.-R.; Mi, Z. One-Step Overall Water Splitting under Visible Light Using Multiband InGaN/GaN Nanowire Heterostructures. ACS Nano 2013, 7, (9), 7886-7893.

9. AlOtaibi, B.; Nguyen, H. P.; Zhao, S.; Kibria, M. G.; Fan, S.; Mi, Z. Highly stable photoelectrochemical water splitting and hydrogen generation using a double-band InGaN/GaN core/shell nanowire photoanode. Nano Lett. 2013, 13, (9), 4356-61.

10. Doppalapudi, D.; Basu, S. N.; Ludwig, K. F.; Moustakas, T. D. Phase separation and ordering in InGaN alloys grown by molecular beam epitaxy. J. Appl. Phys. 1998, 84, (3), 13891395.

11. Wang, Y.; Vanka, S.; Gim, J.; Wu, Y.; Fan, R.; Zhang, Y.; Shi, J.; Shen, M.; Hovden, R.; Mi, Z. An $\operatorname{In}_{0.42} \mathrm{Ga}_{0.58} \mathrm{~N}$ tunnel junction nanowire photocathode monolithically integrated on a nonplanar Si wafer. Nano Energ. 2019, 57, 405-413.

12. Wang, Y.; Wu, Y.; Sun, K.; Mi, Z. A quadruple-band metal-nitride nanowire artificial photosynthesis system for high efficiency photocatalytic overall solar water splitting. Mater. Horizons 2019, 6, (7), 1454-1462.

13. Gu, J.; Yan, Y.; Young, J. L.; Steirer, K. X.; Neale, N. R.; Turner, J. A. Water reduction by a p-GaInP 2 photoelectrode stabilized by an amorphous $\mathrm{TiO}_{2}$ coating and a molecular cobalt catalyst. Nat. Mater. 2016, 15, (4), 456-60.

14. Verlage, E.; Hu, S.; Liu, R.; Jones, R. J. R.; Sun, K.; Xiang, C.; Lewis, N. S.; Atwater, H. A. A monolithically integrated, intrinsically safe, $10 \%$ efficient, solar-driven water-splitting system based on active, stable earth-abundant electrocatalysts in conjunction with tandem III-V light absorbers protected by amorphous $\mathrm{TiO}_{2}$ films. Energ. Environ. Sci. 2015, 8, (11), 3166-3172. 
15. Kang, D.; Young, J. L.; Lim, H.; Klein, W. E.; Chen, H.; Xi, Y.; Gai, B.; Deutsch, T. G.; Yoon, J. Printed assemblies of GaAs photoelectrodes with decoupled optical and reactive interfaces for unassisted solar water splitting. Nat. Energ. 2017, 2, 17043.

16. Cheng, W.-H.; Richter, M. H.; May, M. M.; Ohlmann, J.; Lackner, D.; Dimroth, F.; Hannappel, T.; Atwater, H. A.; Lewerenz, H.-J. Monolithic Photoelectrochemical Device for Direct Water Splitting with 19\% Efficiency. ACS Energ. Lett. 2018, 3, (8), 1795-1800.

17. Ra, Y. H.; Wang, R.; Woo, S. Y.; Djavid, M.; Sadaf, S. M.; Lee, J.; Botton, G. A.; Mi, Z. Full-Color Single Nanowire Pixels for Projection Displays. Nano Lett. 2016, 16, (7), 4608-15.

18. Ra, Y.-H.; Rashid, R. T.; Liu, X.; Sadaf, S. M.; Mashooq, K.; Mi, Z. An electrically pumped surface-emitting semiconductor green laser. Sci. Adv. 2020, 6, (1), eaav7523. 